\title{
EXPERIMENTAL AND NUMERICAL ANALYSIS OF THE COMPRESSION THIN-WALLED COMPOSITE PLATE
}

\author{
Katarzyna Falkowicz', Przemysław Mazurek², Patryk Różyło', \\ Paweł Wysmulski' ${ }^{1}$, Wojciech Smagowski ${ }^{3}$
}
1 Faculty of Mechanical Engineering, Department of Machine Design and Mechatronics, Lublin University of Technology, Nadbystrzycka 36, 20-618 Lublin, Poland, e-mail: k.falkowicz@pollub.pl, p.rozylo@pollub.pl, p.wysmulski@pollub.pl
2 Faculty of Mechanical Engineering and Aeronautics, Rzeszow University of Technology, Powstańców Warszawy 12, 35-959 Rzeszow, Poland, e-mail: p.mazurek@prz.edu.pl
3 Faculty of Mechanical Engineering, Department of Applied Mechanics, Lublin University of Technology, Nadbystrzycka 36, 20-618 Lublin, Poland, e-mail: w.smagowski@pollub.pl

Received: 2016.06.09

Accepted: 2016.07 .05

Published: 2016.09.01

\begin{abstract}
The subject of research is a rectangular plate with a cut-out subjected to regular compression. The plate articulately supported on the short side edges, made of a composite with high strength properties. The study concerned the numerical finite element analysis linear and nonlinear stability of the structure and the experimental validation of the results. The instrument used was a numerical program ABAQUS ${ }^{\circledR}$.
\end{abstract}

Keywords: numerical analysis, critical force, buckling, postbuckling.

\section{INTRODUCTION}

Thin-walled construction, are a very specific group of supporting structures which have very good strength and stiffness indicators in relation to their own weight. These are the decisive features for the use of thin-walled composite elements as support elements in the automotive [2], the aerospace $[16,18,22]$ or the space industry where there are quite rigorous performance requirements regarding the structure work in the complex load conditions. The specificity of thinwalled supporting structures causes that in case of a specific state of the load its elements can be exposed to the possibility of loss of stability within the exploitation load conditions. Therefore, in addition to the requirements of strength with regard to the thin-walled structures there are also relevant requirements regarding stiffness, which help protect the structure from premature destruction as a result of loss of stability of its elements. Thus, knowledge about the value of critical load at which the structure loses stability is one of the very important issues. In some cases, the critical load can lead to the destruction of structure $[1,26]$, then they are treated as a limit load. The exemplary papers dealing with local buckling of thin-walled structures are those written by Davis and Hancock [4, 27], Graves-Smith [5] and Kumar [19]. The buckling of open section beams was the subject of the papers [3,8]. Most of the thin-walled structures are characterized by the ability to work after the loss of stability (this concerns mainly the elastic buckling of local character) in the so-called. the elastic post-critical condition. In such cases, definition of limit load structure elements requires analysis also able post-critical until the destruction of the structure. In the worldwide literature, studies into nonlinear problems of stability of thin-walled structures can be found easily, for example Koiter [13], Debski [5, 7], Kopecki [15, 17], Mania [21] and [9]. 
In this article the original conception of a thin-walled plate element with a central cut-out for use as the elastic element has been examined. The research included linear and non-linear numerical analysis of structures by using finite element method and experimental verification of the FEM. It is worth mentioning that the numerical is now largely applicable in reference to the real structures $[6,10,11,20,24,25]$.

\section{SUBJECT OF STUDY}

The subject of research was the thin-walled plate with a central rectangular cut-out made of carbon-epoxy composite, the material data presented in Table 1.

The structure of the laminate was composed of 8 layers of the same thickness of $0.131 \mathrm{~mm}$ in a symmetric system of layers with respect to the median plane of the composite. Research were conducted on a composite plate at configuration of the layers $(90 /-45 / 45 / 0)$ s. Diagram geometric of the plate with cut-out shows Figure 1 . The analyzed plate had a symmetrical cut-out in the middle. The dimensions of the cut-out are following height: $\mathrm{a}=100 \mathrm{~mm}$ and width: $\mathrm{b}=30 \mathrm{~mm}$.

\section{RESEARCH METHODOLOGY}

In the paper presents an analysis of the critical state of axial compression of thin-walled composite structure with a central rectangular cutout, pivotally supported at both ends and additionaly the solution of the nonlinear buckling, in which calculations were carried out on models with initial of geometric imperfection corresponding higher flexural-torsional buckling form of construction. The scope of work included conducting experimental research on the actual design and the execution of numerical simulation using the finite element method. Conducted experimental studies on the produced thin-walled composite plate allowed the observation of the actual behavior of the structure in a critical and post-critical state, while enabling the identification of the form of buckling and to determine the value of the critical load. Conducted simultaneously numerical simulations were carried out in order to elaboration adequate models MES verified experimentally, allowing modeling of problems of buckling of composite thin-walled structures, in a faithful way of imitating the behavior of the real structure.

Table 1. Mechanical properties of carbon-epoxy composite M12/35\%/UD134/AS7/300

\begin{tabular}{|c|c|c|c|c|c|c|c|c|}
\hline \multirow{2}{*}{\multicolumn{2}{|c|}{$\begin{array}{l}\text { Tensile strength [MPa] } \\
\qquad \mathrm{F}_{\mathrm{TU}} \\
\end{array}$}} & \multicolumn{2}{|c|}{ Tensile modulus [GPa] } & \multirow{3}{*}{$\begin{array}{c}\begin{array}{c}\text { Poisson's } \\
\text { ratio [-] }\end{array} \\
\mathrm{v}_{12} \\
0^{\circ}\end{array}$} & \multirow{3}{*}{$\begin{array}{c}\begin{array}{c}\text { Shear } \\
\text { strength } \\
\text { [MPa] }\end{array} \\
\mathrm{F}_{\mathrm{SU}} \\
\pm 45^{\circ}\end{array}$} & \multirow{3}{*}{$\begin{array}{c}\begin{array}{c}\text { Shear } \\
\text { modulus } \\
{[\mathrm{GPa}]}\end{array} \\
\mathrm{G}_{12} \\
\pm 45^{\circ}\end{array}$} & \multirow{2}{*}{\multicolumn{2}{|c|}{$\begin{array}{c}\begin{array}{c}\text { Compression strength } \\
{[\mathrm{MPa}]}\end{array} \\
\mathrm{F}_{\mathrm{CU}} \\
\end{array}$}} \\
\hline & & \multirow{2}{*}{$\begin{array}{l}\mathrm{E}_{1} \\
0^{\circ}\end{array}$} & \multirow{2}{*}{$\begin{array}{c}\mathrm{E}_{2} \\
90^{\circ}\end{array}$} & & & & & \\
\hline $0^{\circ}$ & $90^{\circ}$ & & & & & & $0^{\circ}$ & $90^{\circ}$ \\
\hline 1867 & 26 & 131.71 & 6.36 & 0.32 & 100.15 & 4.18 & 1531 & 214 \\
\hline
\end{tabular}
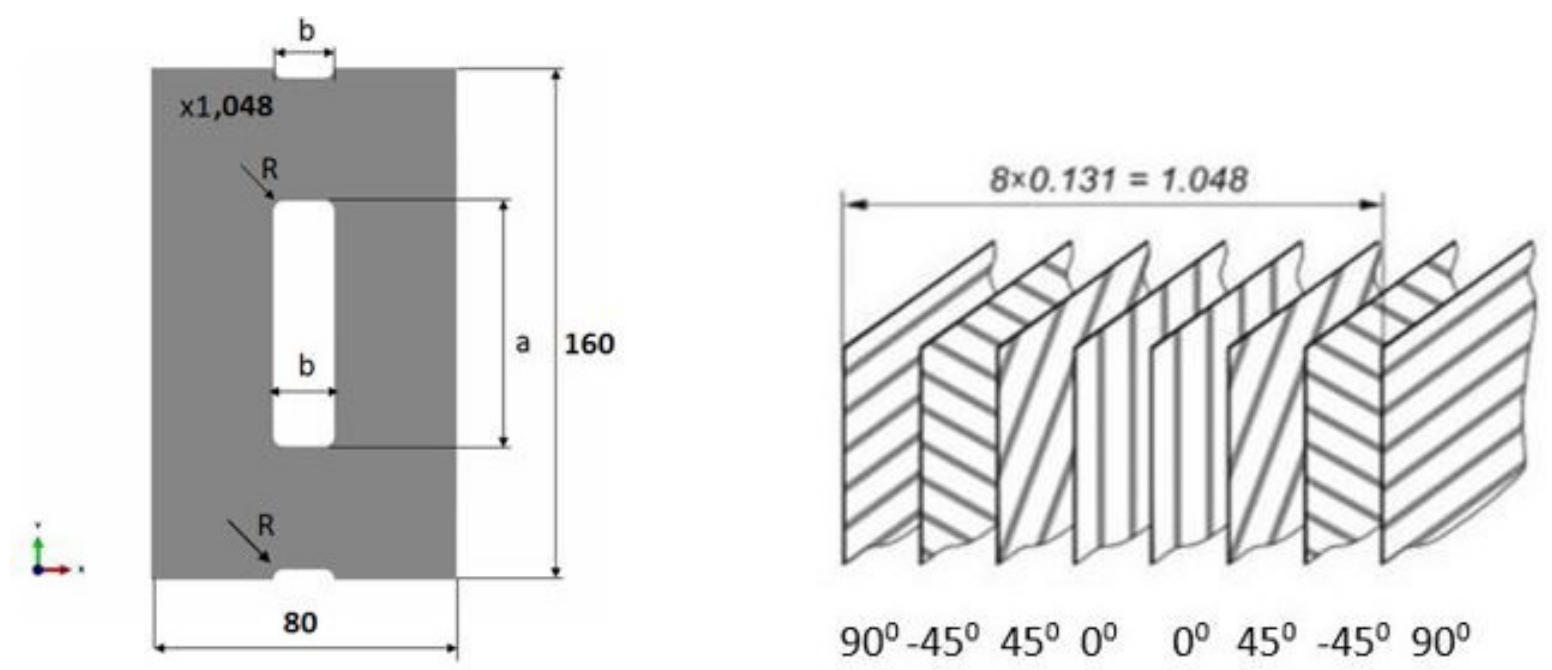

Fig. 1. Dimensions and structure of the thin-walled plate with cut-out and the composite layer system 


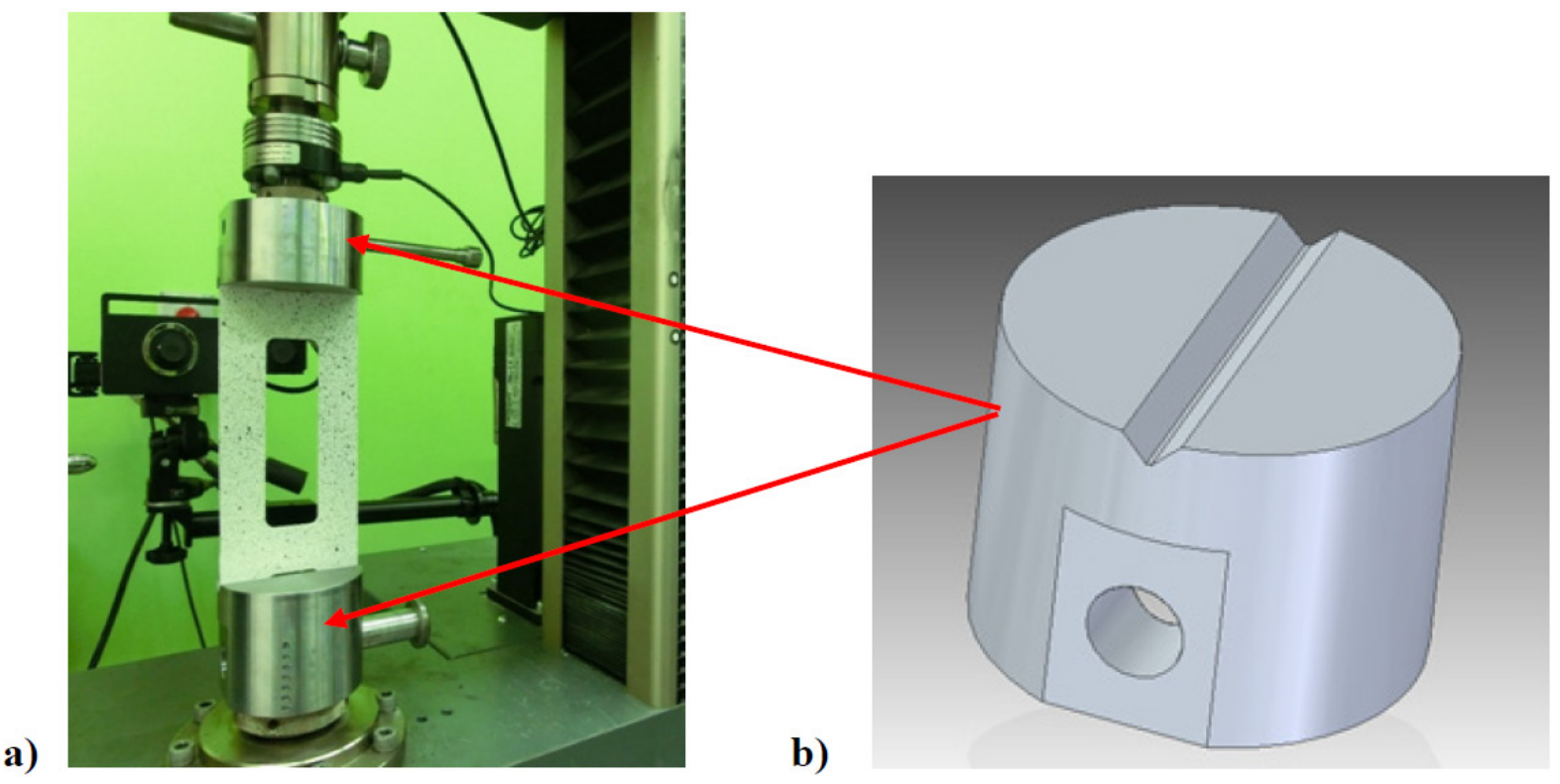

Fig. 2. Experimental research: a) general view of the test stand with mounted sample, b) ideological diagram of the handle

\section{EXPERIMENTAL RESEARCH}

Experimental studies of axial compression of the composite panel was conducted on a universal testing machine, Zwick / Roell Z050 at a constant crosshead displacement rate of $2 \mathrm{~mm} / \mathrm{min}$. In order to ensure conditions of an articulated support of end edges of plates, designed and manufactured special handles for axial compression of the sample. A general view of construction of mounting plate on the bench along with the ideological diagram of the handle shown in Figure 2.

In experimental study of buckling of thinwalled structures very important detailed registration of the relevant parameters of the test. In order to adequately describe the critical and postcritical state of structures, it is necessary to register not only the load, but also displacement at selected points of structure. In the context of the carried out of studies to measure the deflection of plate the ARAMIS system is used. During the measurements were recorded: the duration of the measurement, the compression force of sample, crosshead displacement and deflection of sample. As a result were obtained measurements, on the basis of which characteristics of the disc were determined, to assess the critical state.

Occurring in the course of experimental research of all kinds of imperfections caused by various independent factors make it difficult to precisely determine the value of the critical load. In such cases, used the methods which allow to determine the local critical load based on measurements obtained in experimental studies. In the present study to assess the value of the critical load were used methods $\mathrm{P}-\mathrm{w}^{2}$ and $\mathrm{P}-\mathrm{w}^{3}$ [28]. The applied techniques are associated with the need to perform calculations of approximation, which are allow to fit the function describing analyzed phenomenon, to the received experimentally of test results.

\section{NUMERICAL ANALYSIS}

Numerical calculations were carried out in two stages. The first stage were a critical analysis of the structure by using a linear stability analysis „buckling analysis”, allowing the designation of critical compression load of the plate and the corresponding forms of buckling. The second stage of the calculations were the solution of the problem of nonlinear stability, in which calculations were carried out on the model with geometric imperfection corresponding to flexural-torsional form of buckling of structure. The work tool which was used in research calculations is a numerical program ABAQUS. In the process of discretization of the analyzed element applied coating finite elements of type SHELL which having six degrees of freedom at each node. The type of finite element which was used to build the model of discrete constituted the four-nodal shell elements with reduced in- 


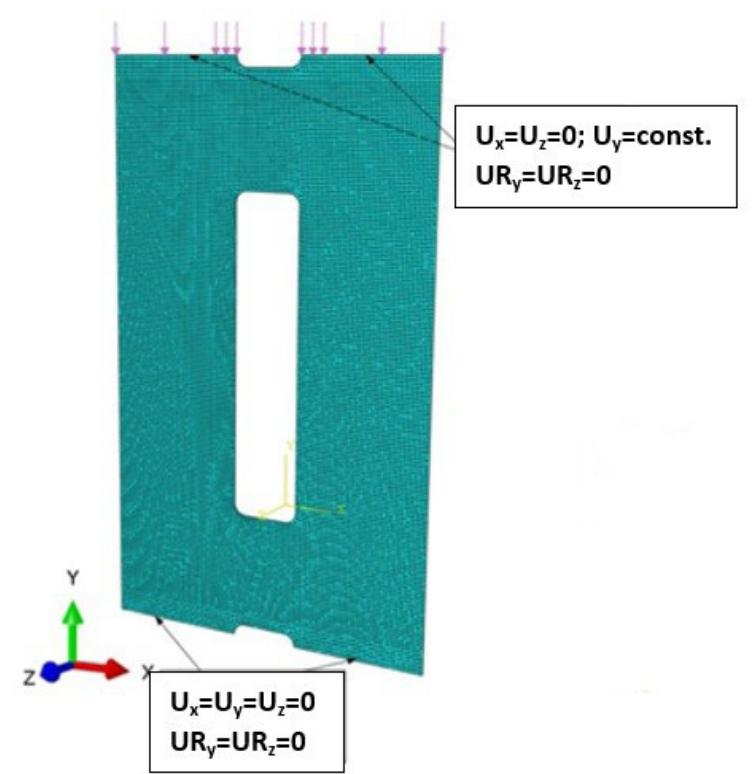

Fig. 3. Discrete model of plate

tegration with the designation of S4R. In order to modeling the structure of the laminate was used for modeling technique known as LayupPly, throughout mapped of the configuration of the layers of the composite. The properties of the composite material were described by defining an orthotropic model of material in a flat state of stress. The mechanical properties of the material were adopted in accordance with Table 1. The boundary conditions correspond to the implementation of an articulated support of the composite panel by the task of zero level of displacement nodes situated on the upper and lower edge of the plate on the directions perpendicu- lar to the wall of the plate. In addition, has been blocked displacement of the nodes belonging to the lower edge for the vertical direction. Load of model was realized by load the upper edge of plate to provide uniform compression to the vertical direction. General view of the numerical model of the structure presents Figure 3.

This way of definition of boundary conditions and load of model is allow to reproduce the conditions for the implementation of experimental research on the testing machine.

\section{RESULTS AND DISCUSSION}

The carried out of experimental research of compressed composite plate with cut-out have provided the information for an assessment the state of deformation of the real structure as a function of external load. The obtained research results allow to make a qualitative and a quantitative analysis of the critical and before critical state based on the registered parameters of the sample. The identification of the critical state of the tested element was carried out on the basis of the obtained form of buckling which is the first form of loss of stability and the corresponding its value of the critical load. The designated experimentally critical value was the basis for verification of the results of FEM numerical calculations. The recived the lowest form of buckling of tested composites' plate has shown in Figure 4.

The qualitative analysis of the results confirms the compatibility designated by numerical a)

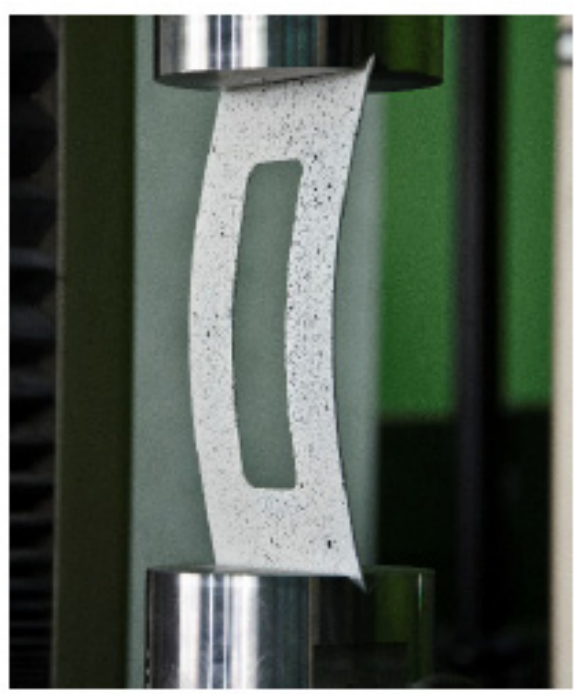

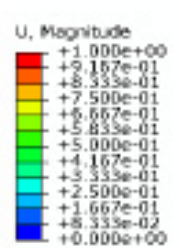

b)
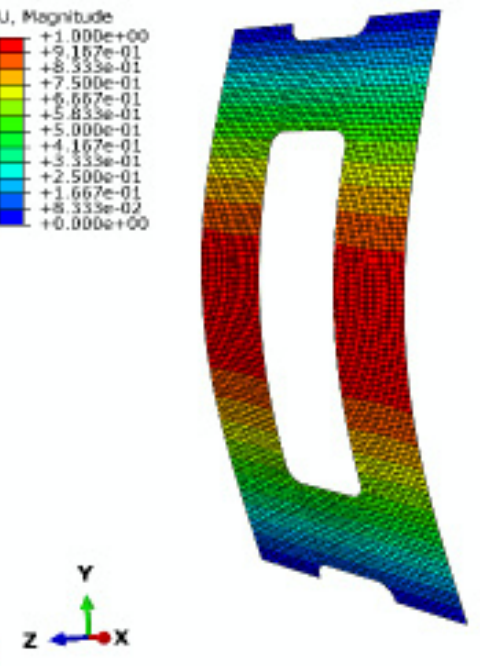

Fig. 4. The lowest form of plate buckling about the [90/-45/45/0]s layout:

a) experimental research, b) numerical analysis 


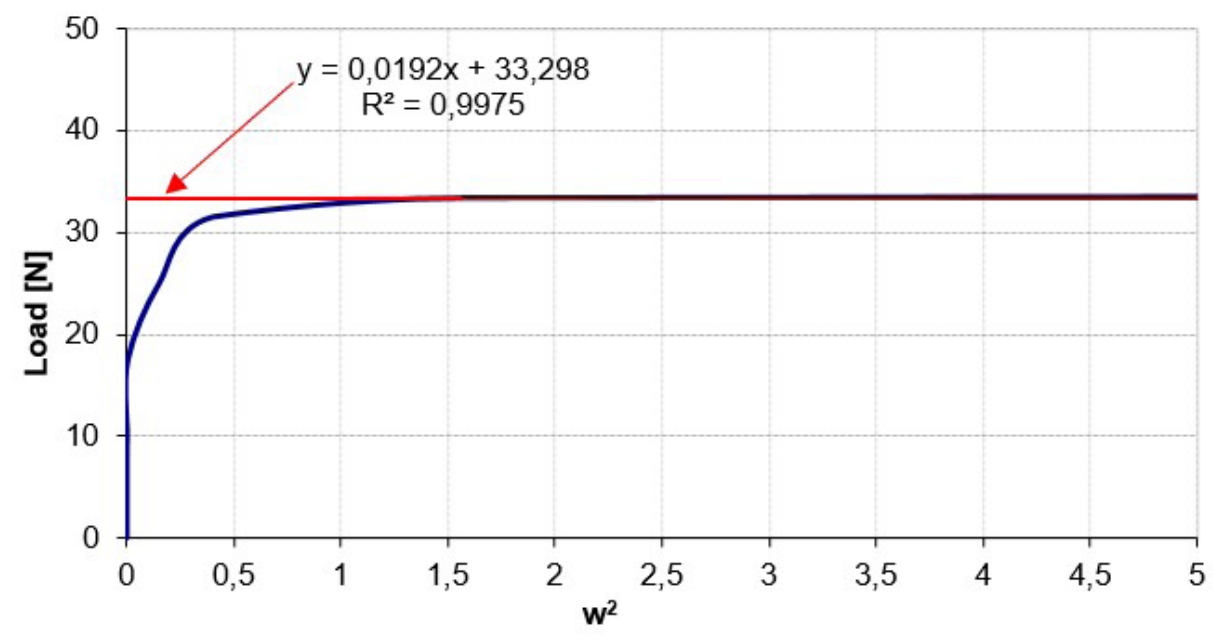

Fig. 5. Example of the result obtained with $\mathrm{P}-\mathrm{w}^{2}$ method

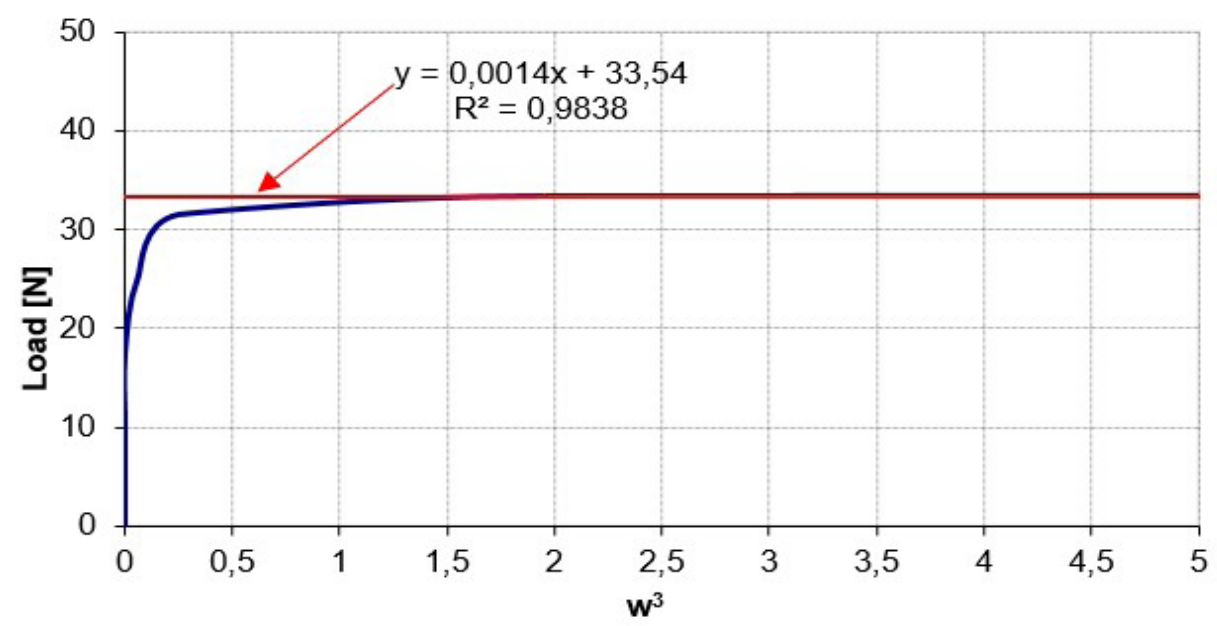

Fig. 6. Example of the result obtained with $\mathrm{P}-\mathrm{w}^{3}$ method

Table 2. The average values of critical force - a summary of results

\begin{tabular}{|c|c|c|c|c|}
\hline \multicolumn{3}{|c|}{ Critical Force $\mathrm{P}_{\text {cr }}[\mathrm{N}]$} \\
\hline \multicolumn{2}{|c|}{ Experimental Research } & \multirow{2}{*}{ FEM Calculations } & $\mathrm{P}^{2} \mathrm{w}^{2}$ & $\mathrm{P}^{2}-\mathrm{w}^{3}$ \\
\cline { 5 - 5 } $\mathrm{P}-\mathrm{w}^{2}$ & $\mathrm{P}-\mathrm{w}^{3}$ & & 9.37 & 8.71 \\
\hline 33.30 & 33.54 & 36.74 & 9.37 \\
\hline
\end{tabular}

calculations forms of buckling of thin-walled plate with the form of deformation obtained in experimental researches (Fig. 4).

The quantitative analysis of the results allows to specify the value of the critical load corresponding to the obtained the lowest form of loss of stability of the analyzed composite plate. On the basis of the carried out in experimental research a deformation measurements as a function of external load were determined average values of the critical force for the analyzed plate with using $\mathrm{P}-\mathrm{w}^{2}$ (Fig. 5) and $\mathrm{P}-\mathrm{W}^{3}$ (Fig. 6) methods, which then were compared with the results of FEM numerical calculations (Table 2).

The presented in Table 2 results show a qualitative and a quantitative coincidence of critical load values of numerical calculations with experimental results. The designated the value of the critical force by these methods was fraught with error not exceeding $10 \%$, which in the case of thin-walled structures stability analysis indicates a high consistency of results. The received the lowest flexural form of buckling does not ensure the stable plate work as a elastic element. 
a)

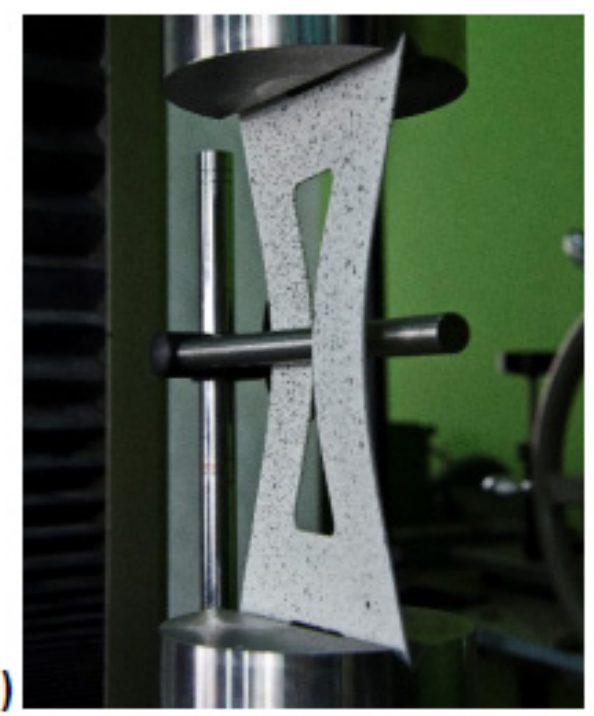

b)

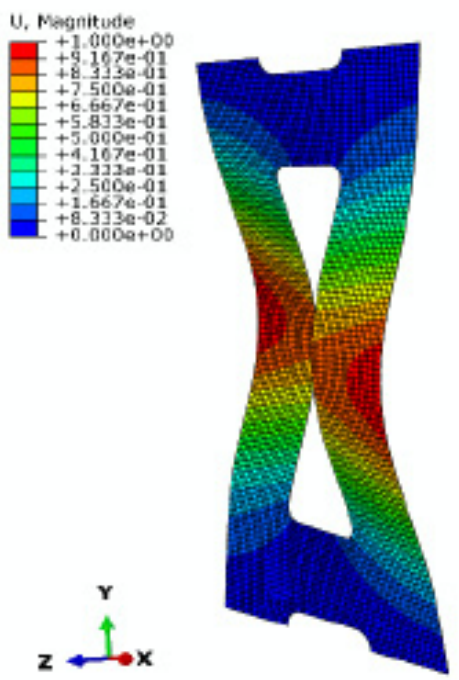

Fig. 7. The higher flexural-torsional form of plate buckling about the $[90 /-45 / 45 / 0]$ s layout:

a) experimental research, b) numerical analysis

The small increases of load can result in this case to fast destruction of the structure. For this reason, in order to ensure the stable plate work in the postcritical range, capable to carrying of higher values of load, it need to force its work by higher flexural-torsional form of buckling. For this purpose, in the experimental research applied the extortion of higher form of buckling by the introduction of the deflection using a steel rod placed in the mid-plate height (Fig. 7).

In the second stage of the calculation, constituting the solution of the nonlinear stability issue, plate work in postcritical state with forced higher, flexural-torsional form of plate buckling was analyzed (Fig. 8).

During the structures' loading in the postcritical range, the same parameters of sample as in the critical range were registered. Postcritical equilibrium paths in the form of force-deflection graphs, allowing define the characteristic of tested plate in the postcritical range were determined. Postcritical equilibrium paths obtained by numerical method (FEM) in the graph with measurements of experimental research are presented (Fig. 9).

As can be seen, the postcritical equilibrium path which was obtained by experiment, shows a)

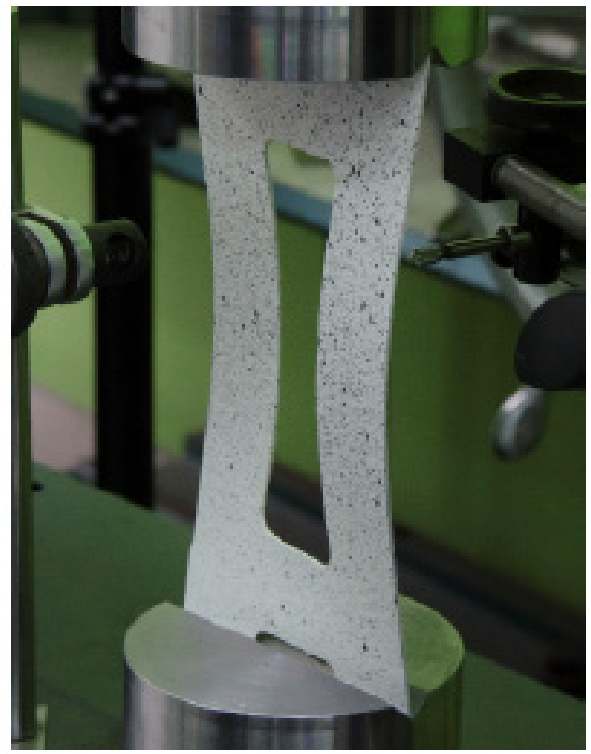

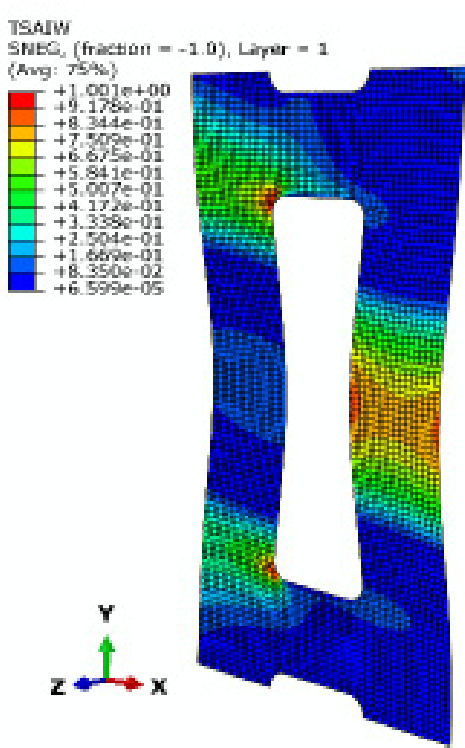

Fig. 8. The higher (stable) flexural-torsional form of plate buckling about the [90/-45/45/0]s layout: a) experimental research, b) numerical anlysis 


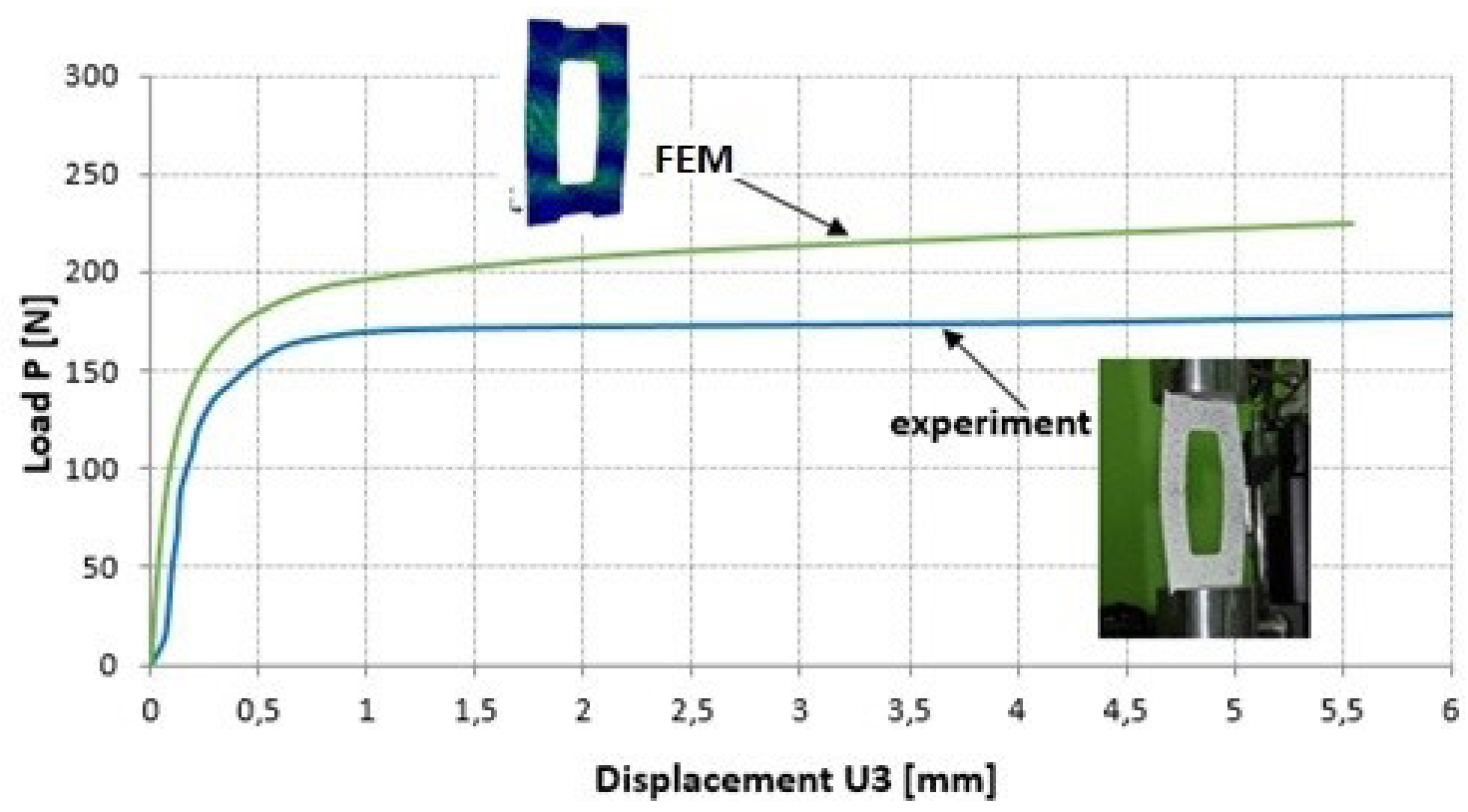

Fig. 9. Postcritical equlibrium paths - comparison of FEM results and experimental research

less stiffness than the results of numerical calculations. However, the maximum differences do not exceed $27 \%$. This fact results from the higher numerical model' stiffness for which are preserved the ideal conditions of analysis, which is consistent with the results of similar studies published in the literature.

\section{CONCLUSIONS}

Presented at work results of FEM numerical calculations have been successfully verified by experimental results. The researches on the real structures have allowed to designation of the value of the critical load with the use of methods based on the results of experimental measurements. The obtained results of research correspond with the results of numerical calculations, which is expressed in satisfactory the compatibility of critical load, the difference does not exceed $10 \%$.

The postcritical equilibrium paths, for the real structure and for the numerical model, retain the staid character, confirming the validity of the adopted in the numerical calculation of plate model, allowing for the description of the nonlinear stability issue. The resulting in the case of the real construction the stable form of work, corresponding to the higher, flexural-torsional form of buckling, indicates on the possibility to use a thin-walled plate elements with a cut-out for use as the elastic elements.
In carried out studies recived a qualitative compatibility of the lowest form of buckling and the deformation form of the structure in the postcritical range, corresponding to the forced work with a higher, flexural-torsional form. Simultaneously, the satisfactory a quantitative of compliance of the numerical analysis results with the experimental results, confirm the adequacy of the developed numerical model, which in this case maps the behavior of real construction.

\section{REFERENCES}

1. Banat D., Mania R.J., Comparison of failure criteria application for FML column buckling strength analysis. Composite Structures, 140, 2016, 806-815.

2. Bambach M.R., Fibre composite strengthening of thin-walled steel vehicle crush tubes for frontal collision energy absorption. Thin-Walled Structures, 66, 2013, 15-22.

3. Czapski P., Kubiak T., Influence of Fibre Arrangement on the Buckling Load of Composite Plates . Analytical Solution Fibres and Textiles in Eastern Europe, 113 (5), 2015, 92-98.

4. Davids J., Hancock G.J., Compression tests of long welded I-section columns. J Struct Eng, 112 (10), 1986, 2281-2297.

5. Debski H., Eksperimental investigation of postbuckiling behavior of composite column with tophat cross-section. Maitenence and Reliability, 15 (2), 2013, 106-110.

6. Debski H., Koszalka G., Ferdynus M., Application of FEM in the analysis of the structure of a trailer 
supporting frame with variable operation parameters, Maitenence and Reliability, 2, 2012, 107-113.

7. Debski H., Teter A., Kubiak T., Samborski S., Local buckling, post-buckling and collapse of thin-walled channel section composite columns subjected to quasi-static compression. Composite Structures, 136, 2016, 593-601.

8. Debski Hubert, Teter Andrzej, Kubiak Tomasz, Numerical and experimental studies of compressed composite columns. Composite Structures, 118, 2014, 28-36.

9. Falkowicz K., Ferdynus M., Debski H., Numerical analysis of compressed plates with a cut-out operating in the geometrically nonlinear range. Maintenance and Reliability, 17 (12), 2015, 222-235.

10. Fedorko G., Molnár V., Živčák J., Dovica M., Husáková N., Failure analysis of textile rubber conveyor belt damaged by dynamic wear. Eng. Fail. Anal., 28, 2013, 103-114.

11. Ferdynus M., An energy absorber in the form of a thin-walled column with square cross-section and dimples. Maintenance and Reliability, 15 (3), 2013, 253-258.

12. Graves-Smith T.R., The local buckling of box girders under bending stresses. Int J Mech Sci. 11, 1969, 603-612.

13. Koiter W.T. Elastic stability and post-buckling behavior. In Proceedings of the Symposium on Nonlinear Problems. Wisconsin: Univ. of Wisconsin Press, 1963, 257-275.

14. Kopecki T., Numerical-experimental analysis of the post-buckling state of a multi-segment multimember thin-walled structure subjected to torsion. Journal of Theoretical and Applied Mechanics, 49 (1), 2011, 227-242.

15. Kopecki T., Numerical and experimental analysis of post-critical deformation states in a tensioned plate weakned by a crack. Journal of Theoretical and Applied Mechanics, 48 (1), 2010, 45-70.

16. Kopecki T., Bakunowicz J., Lis T., Post-critical deformation states of composite thin-walled aircraft load-bearing structures. Journal of Theoretical and Applied Mechacnics, 54 (1), 2016, 195-204.

17. Kopecki T., Mazurek P., Determination of stress distribution patterns in post-critical deformation states of thin-walled skins subjected to operating loads. Maitenence and Reliability, 16 (4), 2014, 608-615.
18. Kopecki T., Świech Ł., Experimental and numerical analysis of post-buckling deformation states of integrally stiffened thin-walled components of loadbearing aircraft structures. Journal of Theoretical and Applied Mechacnics, 52 (4), 2014, 905-916.

19. Kumar D., Singh S.B., Effects of boundary conditions on buckling and postbuckling responses of composite laminate with various shaped cutouts. Composites Structures, 92, 2010, 769-779.

20. Lonkwic P., Różyło P.: Theoretical and experimental analysis of loading impact from the progressive gear on the lift braking distance with the use of the free fall method. Advances in Science and Technology Research Journal, 10 (30), 2016, 103-109.

21. Mania R.J., Kolakowski Z., Bienias J., Jakubczak P., Majerski K.: Comparative study of FML profiles buckling and postbuckling behaviour under axial loading. Composite Structures, 134, 2015, 216-225.

22. Orifici A.C., Thomson R.S., Degenhardt R., Kling A., Rohwer K., Bayandor J., Degradation investigation in a postbuckling composite stiffened fuselage panel. Composite Structures, 82, 2008, 217-224.

23. Paszkiewicz M., Kubiak T., Selected problems concerning determination of the buckling load of channel section beams and columns. Thin-Walled Structures, 93, 2015, 112-121.

24. Różyło P.: Optimization of I-section profile design by the finite element method. Advances in Science and Technology Research Journal, 10 (29), 2016, 52-56.

25. Rudawska A., Debski H., Experimental and numerical analysis of adhesively bonded aluminium alloy sheets joints. Maitenence and Reliability, 1, 2011, 4-10.

26. Teter A., Debski H., Samborski S., On buckling collapse and failure analysis of thin-walled composite lipped-channel columns subjected to uniaxial compression. Thin-Walled Structures, 85, 2014, 324-331.

27. Wysmulski P., Dębski H., Różyło P., Falkowicz K., A study of stability and post-critical behaviour of thinwalled composite profiles under compression, Maintenance and Reliability, 18 (4), 2016, 632-637

28. Zaraś J., Królak M., Kotełko M.: Metody doświadczalne wyznaczania obciążeń krytycznych i analizy zachowania się elementów konstrukcji w stanie zakrytycznym. X Krajowa Konferencja Wytrzymałości Materiałów i Badania Materiałów, Kudowa-Zdrój 20-22 wrzesień, 2006. 